\title{
Sulfoquinovosylmonoacylglycerols regulating intestinal inflammation in co-culture system from the brown alga Turbinaria ornata
}

\author{
Seon Min Lee ${ }^{1}$, Na-Hyun Kim ${ }^{1}$, Yeong Kwang Ji ${ }^{2}$, Yun Na Kim ${ }^{3}$, You-Jin Jeon ${ }^{4}$, \\ Jeong Doo Heo ${ }^{1}$, Eun Ju Jeong ${ }^{3}$ and Jung-Rae Rho ${ }^{2, *}$ \\ ${ }^{1}$ Gyeongnam Department of Environment \& Toxicology, Korea Institute of Toxicology, Munsan 5834, Korea \\ ${ }^{2}$ Department of Oceanography, Kunsan National University, Gunsan 54150, Korea \\ ${ }^{3}$ Department of Agronomy and Medicinal Plant Resources, Gyeongnam National University of Science and Technology, \\ Jinju 52725, Korea \\ ${ }^{4}$ Department of Marine Life Sciences, Jeju National University, Jeju 63243, Korea
}

The inflammatory bowel diseases (IBD) including ulcerative colitis and Crohn disease are characterized by chronic inflammation throughout the gastrointestinal tract. The prevalence of IBD has been increasing worldwide, and has sometimes led to irreversible impairment of gastrointestinal structure and functions. In the present study, we identified a new sulfoquinovosylmonoacylglycerols (SQMG) (1) together with two known SQMGs (2 and 3) regulating intestinal inflammation from the brown alga Turbinaria ornata. The anti-inflammatory properties of two bioactive SQMGs, 1 and 2 were evaluated using an in vitro co-culture system consisting of human epithelial Caco-2 cells and PMA (phorbol 12-myristate 12-acetate)-differentiated THP-1 macrophages. Treatment with 1 or $\mathbf{2}$ inhibited the production nitric oxide and prostaglandin $\mathrm{E}_{2}$ induced by lipopolysaccharide and interferon $\gamma$ challenge. The expressions of inducible nitric oxide synthase and cyclooxygenase 2 were markedly down-regulated in response to inhibition of nuclear factor $\mathrm{kB}$ translocation to nucleus. These findings suggest the potential use of the brown alga T. ornata and its biologically active metabolites SQMGs as pharmaceutical adjuvants in the treatment of inflammation-related diseases, including IBD.

Key Words: co-culture; inflammation; inflammatory bowel disease; sulfoquinovosylmonoacylglycerol; Turbinaria ornata

\section{INTRODUCTION}

Inflammatory bowel disease (IBD) is a chronic inflammatory disease, including ulcerative colitis (UC) and Crohn disease (CD). Characteristic chronic inflammation of the gastrointestinal tract observed in IBD sometimes causes irreversible damage to the gastrointestinal structure and functions. The two main types of IBD, UC and $\mathrm{CD}$, have quite different clinical and pathological features. Clinical features of CD mainly include abdomi- nal pain, diarrhea, narrowing of the intestinal lumen, and pathological features lead to intestinal obstruction, including scleritis, granulomas, and fistula (Loftus and Sandborn 2002). On the other hand, UC is characterized by lower abdominal pain, diarrhea, rectal bleeding, frequent and bloody feces (Bouma and Strober 2003). Intestinal homeostasis disorders in IBD are due to inadequate and exaggerated mucosal immune responses to the nor-
(9) $\$$ This is an Open Access article distributed under the terms of the Creative Commons Attribution Non-Commercial License (http://creativecommons.org/licenses/by-nc/3.0/) which permits unrestricted non-commercial use, distribution, and reproduction in any medium, provided the original work is properly cited.
Received January 1, 2020, Accepted May 23, 2020

* Corresponding Author

E-mail: jrrho@kunsan.ac.kr

Tel: +82-63-469-4606, Fax: +82-63-465-3917 
mal components of mucosal microflora, as evidenced by numerous studies involving clinical patients and credited animal models (Bouma and Strober 2003). During the onset and progression of IBD, the mucosal epithelial barrier is damaged, and the intestinal flora causes and induces an abnormal intestinal immune response with a subsequent inflammation (Abraham and Cho 2009).

Marine algae are increasingly targeted for their bioactive metabolites that have the potential to be used in future medicine (Blunt et al. 2013, Wang et al. 2017, Alves et al. 2018, Fernando et al. 2019). The organisms produce extensive bioactive compounds including polyphenols, polysaccharides, sterols, fatty acids, peptides, pigments, and halogenated compounds, which exhibit antioxidant, anti-inflammatory, anticancer, antidiabetic, tyrosinase inhibitory and ultraviolet-protective effects (Faulker 2001, Cardozo et al. 2007). In a recent search for antiinflammatory secondary metabolites that regulate intestinal inflammation in marine algae, the extract of brown alga Turbinaria ornata (Turner) J. Agardh showed attractive activity. To evaluate intestinal anti-inflammatory activity, an advanced in vitro co-culture system combining Caco-2 epithelial and THP-1 macrophage cells was established and applied. The differentiated Caco- 2 cells are known to provide properties similar to human intestinal tissue, such as transport and permeability of substances (Rubas et al. 1993, Lennernäs et al. 1996). This co-culture system provides characteristic and more representative human intestine-like model (Kämpfer et al. 2017).

T. ornata is known as a kind of brown algae which is distributed throughout the world. It has been reported that a cytotoxic secosqualene carboxylic acid and turbinaric acid was isolated from T. ornata collected in southern area of Japan and cytotoxic sterols were identified from the organism collected in the southernmost tip of Taiwan (Asari et al. 1989, Sheu et al. 1997). Besides cytotoxic constituents, the extract of $T$. ornata showed potent antioxidant and antibacterial activity which contributed from phenolic compounds (Zubia et al. 2008, Vijayabaskar and Shiyamala 2012). Recently, anti-inflammatory activity $T$. ornata and its active metabolite fucoidan has been reported (Subash et al. 2016). However, the possibility of $T$. ornata in regulating intestinal inflammation has not been reported, and studies of the metabolites of T. ornata remains limited. Hence, in the present study, we evaluated anti-inflammatory potential of $T$. ornata in the treatment of IBD, and attempted to identify bioactive constituents using bioactivity-guided isolation experiments.

\section{MATERIALS AND METHODS}

\section{General experimental procedures}

Optical rotations were measured on a Jasco P-1010 polarimeter (Jasco Co., Ltd, Tokyo, Japan) with a $5 \mathrm{~cm}$ length cell. IR spectrum was recorded on a Jasco FT/IR 4100 spectrometer. Nuclear magnetic resonance (NMR) spectra were measured on a Varian VNMRS $500 \mathrm{MHz}$ spectrometer (Varian Technologies, Santa Clara, CA, USA) in $\mathrm{CD}_{3} \mathrm{OD}$. High resolution electrospray ionization mass spectra were obtained on an SCIEX X500R instrument and tandem mass spectrometry (MS/MS) data was measured on an SCIEX QTRAP 3200 instrument (Applied Biosystems/Sciex, Foster City, CA, USA). High-performance liquid chromatography (HPLC) experiments were performed on an Agilent 1200 system (Agilent, Waldbronn, Germany) consisting of a binary pump (G1312B), autosampler (G1329B), column oven (G1316B), and 1260 infinity evaporative light scattering detector (ELSD). The LPS (Escherichia coli 0127:B8), dimethyl sulfoxide, PMA (phorbol 12-myristate 12-acetate), and monoclonal anti$\beta$-actin antibody were purchased from Sigma-Aldrich (St. Louis, MO, USA). MEM medium, RPMI 1640 medium, fetal bovine serum (FBS), penicillin / streptomycin, and phosphate-buffered saline (PBS) were purchased from Gibco Life Technologies (Grand Island, NY, USA). The DAF-DA assay was purchased from Sigma-Aldrich. Tin protoporphyrin IX (SnPP) was purchased from Porphyrin Products (Logan, UT, USA). Primary antibodies, including inducible nitric oxide synthase (iNOS), cyclooxygenase 2 (COX-2), p65, Lamin B, phospho-p65, IкB $\alpha$, phospho-ERK, ERK, phospho-p38, p38, phospho-JNK, JNK, HO-1, and Nrf2 were purchased from Cell Signaling Technology, Inc. (Beverly, MA, USA). The secondary antibody was purchased from Jackson ImmunoResearch Laboratories, Inc. (West Grove, PA, USA).

\section{Isolation of sulfoquinovosylmonoglycerols from the brown alga Turbinaria ornata}

A specimen of the brown alga T. ornata was collected in Fulhadhoo, Maldives, in August 2017. The freeze-dried specimen $(1.5 \mathrm{~kg})$ was extracted with $90 \%$ aq. EtOH (2 L) twice at room temperature. The extract was concentrated in vacuo to give a semi-solid, which was partitioned into four fractions by solvent extraction: hexane, chloroform, ethyl acetate, and butanol. Among them, the butanol fraction $(600 \mathrm{mg}$ ), obtained from the collaborator (Prof. You-Jin Jeon at Jeju University), was used. For the pur- 


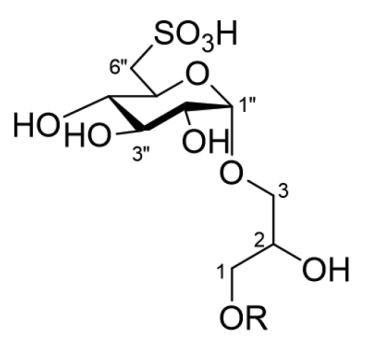<smiles></smiles><smiles>[R]=[V]C(=O)CCCC</smiles>

(2)

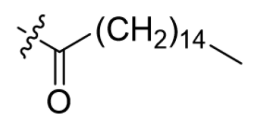

(1)

Fig. 1. Structure of compounds 1-3 isolated from Turbinaria ornata.

pose of removing any lipids, the fraction was first chromatographed on Sephadex LH-20 eluting 100\% $\mathrm{MeOH}$ to yield four fractions: M1 (150 mg), M2 (250 mg), M3 (155 mg), and M4 (50 mg). Fractions M1 and M4 were evaluated as inactive effect on NO inhibition, but M2 and M3 showed good activity. Partial fraction of M2 (60 mg) showing the highest NO inhibition effect and interesting ${ }^{1} \mathrm{H}$ NMR signal was separated again by HPLC using a column Phenomenex C8 $(250 \times 4.6 \mathrm{~mm}, 5 \mu \mathrm{m})$, gradient solvent system as [A: $\mathrm{H}_{2} \mathrm{O}$ with $0.1 \%$ formic acid, B: acetonitrile, from $30 \%$ B to $50 \%$ B for 10 min, then $50 \%$ B to $100 \% \mathrm{~B}$ for $10 \mathrm{~min}$ ], a flow rate of $1.0 \mathrm{~mL} \mathrm{~min}^{-1}$, and an ELSD detector to yield compounds 1 (2.1 mg), 2 (1.2 mg), and 3 (10.4 mg) (Fig. 1).

Compound 1: a colorless oil; $[\alpha]_{\mathrm{D}}{ }^{25}=+32.8$ (c 0.1 , $\mathrm{MeOH}) ;{ }^{1} \mathrm{H}$ and ${ }^{13} \mathrm{C}$ NMR see Table 1 ; high resolution electrospray ionization mass spectroscopy (HRESIMS) $m / z 597.2946[\mathrm{M}-\mathrm{H}]^{-}$(calcd. $m / z$ 597.2950 $[\mathrm{M}-\mathrm{H}]^{-}$for $\mathrm{C}_{27} \mathrm{H}_{50} \mathrm{O}_{12} \mathrm{~S}$ ).

\section{Cell culture}

The human epithelial cell line (Caco-2) and human monocytic cell line (THP-1) were obtained from the American Type Culture Collection (ATCC, Manassas, VA, USA). The Caco-2 cells were cultured in Eagle's minimum essential medium (EMEM; Gibco BRL, Grand Island, NY, USA) containing $20 \%(\mathrm{v} / \mathrm{v})$ FBS and $1 \%(\mathrm{v} / \mathrm{v})$ antibiotics (100 $\mathrm{U} \mathrm{mL}^{-1}$ penicillin and $100 \mu \mathrm{g} \mathrm{mL} \mathrm{m}^{-1}$ streptomycin). THP-1 cells were cultured in RPMI1640 (Gibco BRL) containing $10 \%(\mathrm{v} / \mathrm{v}) \mathrm{FBS}, 1 \%(\mathrm{v} / \mathrm{v})$ antibiotics $\left(100 \mathrm{U} \mathrm{mL}^{-1}\right.$ penicillin and $100 \mu \mathrm{g} \mathrm{mL} \mathrm{m}^{-1}$ streptomycin) and $0.05 \mathrm{mM}$ 2-mercaptoethanol. The cells were incubated in a humidified atmosphere of $95 \%$ air- $5 \% \mathrm{CO}_{2}$. After that, THP1 cells were treated with PMA for macrophage differentiation as below.

\section{Differentiation of THP-1 monocyte to macrophage}

THP-1 cells were differentiated in medium containing $50 \mathrm{nM}$ of PMA for three days followed by incubated in fresh medium without PMA for additional two days (Daigneault et al. 2010).

\section{In vitro co-culture model of intestine}

For establishment of co-culture system that mimics human intestine, Caco- 2 cells were seeded at $3.75 \times 10^{5}$ cells per well on transwell inserts $(0.4 \mu \mathrm{m}$ pore size; Corning CoStar Corp., Cambridge, MA, USA) and maintained

Table 1. The NMR spectral data for compound $1\left(500 \mathrm{MHz}\right.$ for ${ }^{1} \mathrm{H}$, $\left.\mathrm{CD}_{3} \mathrm{OD}\right)$

\begin{tabular}{|c|c|c|}
\hline No. & $\delta_{\mathrm{C}}$, mult & $\delta_{\mathrm{H}}$, mult $(J \mathrm{~Hz})$ \\
\hline 1 & $66.5, \mathrm{CH}_{2}$ & $4.09, \mathrm{dd}(13.5,2.1) ; 4.19, \mathrm{dd}(13.5,6.1)$ \\
\hline 2 & $69.9, \mathrm{CH}$ & $4.09, \mathrm{~m}$ \\
\hline 3 & $70.5, \mathrm{CH}_{2}$ & 3.39 , dd $(9.5,3.9) ; 4.06$, dd $(9.5,2.9)$ \\
\hline $1^{\prime}$ & $175.2, \mathrm{C}$ & - \\
\hline $2^{\prime}$ & $34.9, \mathrm{CH}_{2}$ & 2.36, t (7.6) \\
\hline $3^{\prime}$ & $25.97 / 25.95, \mathrm{CH}_{2}$ & $1.61, \mathrm{~m}$ \\
\hline $4^{\prime}$ & $30.30 / 30.27, \mathrm{CH}_{2}$ & $1.32, \mathrm{~m}$ \\
\hline $5^{\prime}$ & $30.73 / 30.70, \mathrm{CH}_{2}$ & $1.38, \mathrm{~m}$ \\
\hline $6^{\prime}$ & $33.28 / 33.23, \mathrm{CH}_{2}$ & $2.03, \mathrm{~m}$ \\
\hline $7^{\prime}$ & 132.46 / 132.40, CH & $5.59, \mathrm{dt}(15.4,6.6)$ \\
\hline $8^{\prime}$ & 134.53 / 134.46, CH & 5.39 , dd $(15.4,7.1)$ \\
\hline $9^{\prime}$ & $73.79 / 73.75, \mathrm{CH}_{2}$ & $3.94, \mathrm{dt}(7.1,6.9)$ \\
\hline $10^{\prime}$ & 38.47 / 38.45, $\mathrm{CH}_{2}$ & $1.41, \mathrm{~m} ; 1.50, \mathrm{~m}$ \\
\hline $11^{\prime}$ & $26.65 / 26.62, \mathrm{CH}_{2}$ & $1.31, \mathrm{~m}$ \\
\hline $12^{\prime}-15^{\prime}$ & 29.9-30.5, $\mathrm{CH}_{2}$ & $1.28-1.31, \mathrm{~m}$ \\
\hline $16^{\prime}$ & $33.1, \mathrm{CH}_{2}$ & $1.26, \mathrm{~m}$ \\
\hline $17^{\prime}$ & 27.3, $\mathrm{CH}_{2}$ & $1.29, \mathrm{~m}$ \\
\hline $18^{\prime}$ & $14.5, \mathrm{CH}_{3}$ & $0.89, \mathrm{t}(7.1)$ \\
\hline $1^{\prime \prime}$ & $100.1, \mathrm{CH}$ & $4.77, \mathrm{~d}(3.7)$ \\
\hline $2^{\prime \prime}$ & 73.7, CH & 3.40 , dd $(9.3,3.7)$ \\
\hline $3^{\prime \prime}$ & $75.1, \mathrm{CH}$ & $3.64, \mathrm{t}(9.3)$ \\
\hline $4^{\prime \prime}$ & $74.9, \mathrm{CH}$ & 3.06, dd $(9.5,9.3)$ \\
\hline $5^{\prime \prime}$ & $69.8, \mathrm{CH}$ & $4.09, \mathrm{~m}$ \\
\hline $6^{\prime \prime}$ & $54.2, \mathrm{CH}_{2}$ & 2.90, dd $(14.2,9.3) ; 3.34, \mathrm{dd}(14.2,2.0)$ \\
\hline
\end{tabular}


in growth media EMEM for 14-20 days in an incubator at $37^{\circ} \mathrm{C}$ with a $5 \% \mathrm{CO}_{2}$ atmosphere. Culture medium was changed every 3 days until the cells were fully differentiated (TEER value $>1,200 \Omega \cdot \mathrm{cm}^{2}$ ). THP- 1 cells were independently seeded at $8.5 \times 10^{6}$ cells into the bottom plate of 6-well transwell plate in growth media RPMI1640. Then, the insert that is polarized with Caco-2 monolayer was added. The upper chamber reflects the apical side and the lower chamber the basolateral side of the intestinal epithelium (Kleiveland 2015). For evaluation of antiinflammatory activity of the test sample, $1 \mu \mathrm{g} \mathrm{mL}{ }^{-1}$ of LPS was added on the basolateral compartment of plate and then the test sample was added to the apical compartment of plate at the concentration indicated. After $24 \mathrm{~h}$ incubation, the contents of nitrite and inflammatory mediators produced within culture supernatant in the basolateral side were determined.

\section{Measurement of TEER value}

TEER value was measured once a week to test monolayer integrity using a Millicell-ERS (Millipore, Burlington, MA, USA). The TEER was calculated as following:

TEER $\left(\Omega \cdot \mathrm{cm}^{2}\right)=$ Resistance - Blank resistance $(\Omega) \times$ Membrane surface area $\left(\mathrm{cm}^{2}\right)$

\section{Cell viability assay}

Cell viability was measured in THP-1 cells using CCK8 assay (Cell Counting Kit-8, \#CK04; Dojindo Laboratory, Kumamoto, Japan), according to the manufacturer's instructions. Briefly, THP- 1 cells were seeded at $1 \times 10^{4}$ cells per well in 96-well plates and incubated for $24 \mathrm{~h}$. Then, the cells were treated with test sample of various concentrations for $24 \mathrm{~h}$. After incubation, $10 \mu \mathrm{L}$ of CCK- 8 solution was added to each well and incubated for $3 \mathrm{~h}$ at $37^{\circ} \mathrm{C}$. The absorbance was measured using a microplate reader (Bio-Tek Instruments Inc., Winooski, VT, USA) at $450 \mathrm{~nm}$. The experiments were performed in triplicate.

\section{Measurement of $\mathrm{NO}$ and prostaglandin $\mathrm{E}_{2}$ pro- duction}

THP- 1 cells were seeded at $1 \times 10^{4}$ cells per well in 96well plates and incubated for $24 \mathrm{~h}$. The cells were treated with test sample for $1 \mathrm{~h}$, followed by treated with LPS (10 $\mu \mathrm{g} \mathrm{mL}{ }^{-1}$ ) and interferon-gamma (IFN $\gamma ; 10 \mathrm{ng} \mathrm{mL}^{-1}$ ) for $24 \mathrm{~h}$. The content of nitrite produced in culture medium was determined using DAF-DA assay. Briefly, cells were incubated with DAF-DA $\left(3 \mu \mathrm{mol} \mathrm{mL}{ }^{-1}\right)$ at $37^{\circ} \mathrm{C}$ for $20 \mathrm{~min}$.
Then washed the cells and replaced with fresh medium incubated for an additional $20 \mathrm{~min}$. The fluorescence was measured at $495 \mathrm{~nm}$ of excitation and $515 \mathrm{~nm}$ of emission wavelengths with a microplate reader (Bio-Tek Instruments Inc.). The concentration of prostaglandin $\mathrm{E}_{2}$ $\left(\mathrm{PGE}_{2}\right)$ was quantified using an enzyme-linked immunosorbent assay (ELISA) kit (R\&D System, Minneapolis, MN, USA) according to the manufacturer's instructions. The culture medium as applied in ELISA assay without dilution.

\section{Western blot}

Protein isolated form THP-1 cells incubated in coculture system was applied to western blot assay. After incubation of cells with test sample and LPS as indicated, THP-1 cells were washed three times with ice-PBS and extracted with RIPA buffer containing a protease inhibitor cocktail (Santa Cruz Biotechnology, Santa Cruz, CA, USA) for $30 \mathrm{~min}$ on ice. Protein lysates were centrifuged at $13,000 \times \mathrm{g}$ for $30 \mathrm{~min}$ at $4^{\circ} \mathrm{C}$. Thirty micrograms of the lysed proteins quantified by Bradford assay were separated on sodium dodecyl sulfate polyacrylamide gel electrophoresis (8-12\%) at $100 \mathrm{~V}$ and transferred to polyvinylidene difluoride membrane. The membranes were blocked with 5\% nonfat milk in PBST buffer for $1 \mathrm{~h}$ at room temperature. The membranes were incubated with 1:1,000 diluted primary antibodies (Cell Signaling Technology, Inc., Danvers, MA, USA) at $4^{\circ} \mathrm{C}$ overnight. The membranes were washed three times with PBST buffer followed by incubated with 1:10,000 diluted secondary antibodies for $1 \mathrm{~h}$ at room temperature. Bands were visualized using ECL solution (Thermo Scientific, Rockford, IL, USA) and calibrated by the Chemidoc Imaging System (Bio-Rad, Hercules, CA, USA). The density value of the protein bands was normalized to Lamin B (nuclear) or $\beta$-actin (total protein or cytosol).

\section{Statistical analysis}

All data were through Shapiro-Wilk normality test and Levene's equality of variance test by SPSS ver. 17.0 program (SPSS Inc., Chicago, IL, USA). Then, the results were analyzed and converted to graph using Prism ver. 5.00 software (GraphPad Software, San Diego, CA, USA); oneway ANOVA were used for parametric data or KruskalWallis for non-parametric data with Dunnett or Dunns post hoc tests, respectively. Statistical significance is indicated by $\mathrm{p}<0.05$. Data were expressed as the mean \pm standard deviation of three independent experiments. 

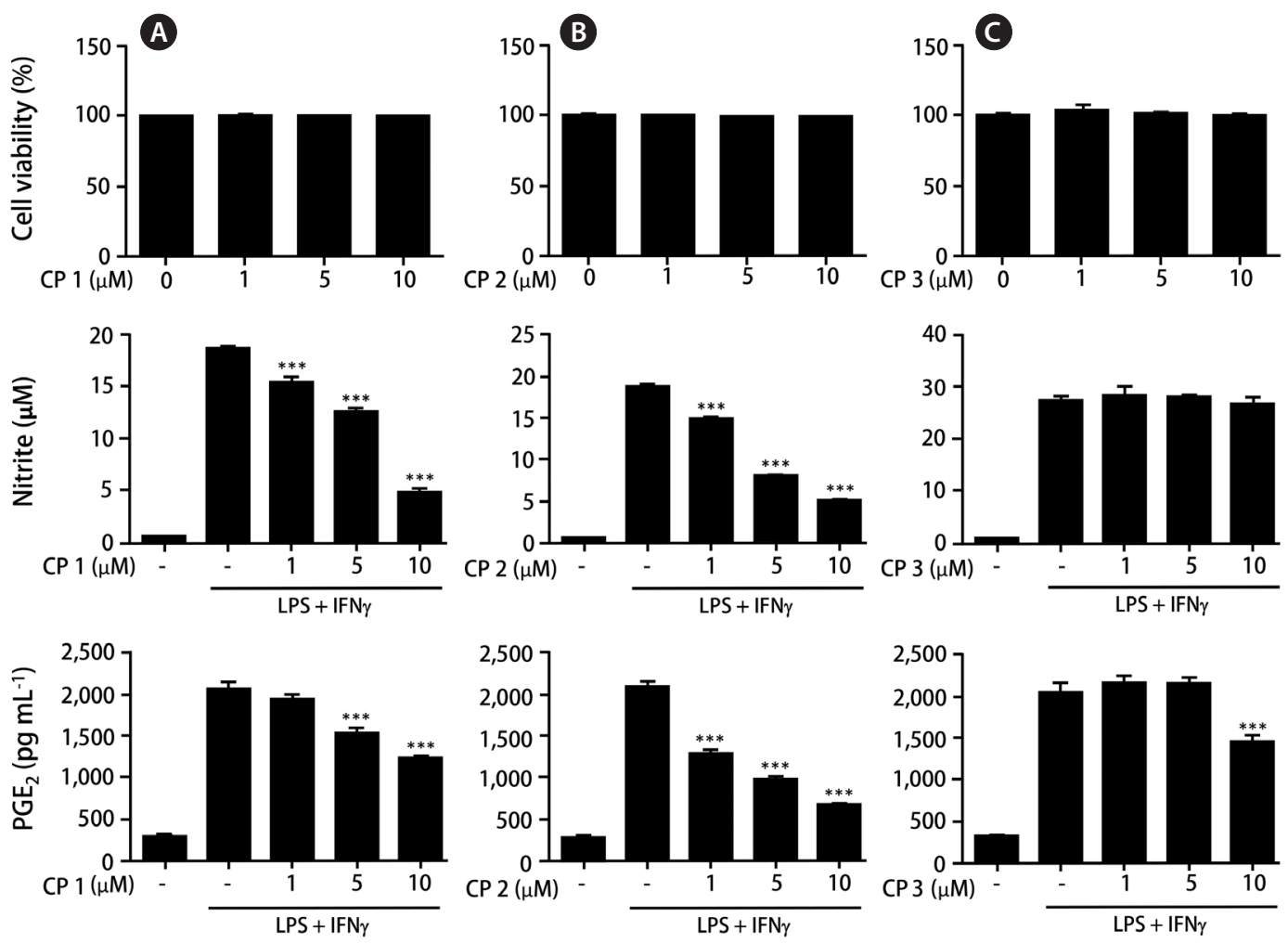

Fig. 2. Cytotoxicity and the effects of compounds 1 (A), 2 (B), and $3(C)$ to inhibit the production of nitric oxide (NO) and prostaglandin $E_{2}\left(P G E_{2}\right)$ in THP-1 cells. For cytotoxicity assay, THP-1 macrophages differentiated by PMA (phorbol-12-myristate-13-acetate) were treated with various concentration of each compound $(1,5$, and $10 \mu \mathrm{M})$ for $24 \mathrm{~h}$. For measurement of NO and PGE 2 content, THP-1 macrophages were treated with each compound $(1,5$, and $10 \mu \mathrm{M})$ followed by co-treated with lipopolysaccharide (LPS) and interferon $\gamma$ (IFN $)$ for $24 \mathrm{~h}$. CP, compound. Results are presented as the mean \pm standard deviation of triplicate experiments. ${ }^{* * *} \mathrm{p}<0.001$ compared to LPS-treated cells.

\section{RESULTS}

\section{Anti-inflammatory sulfoquinovosylmonoacylg- lycerols from the brown alga Turbinaria ornata using bioactivity-guided separation}

Four fractions (M1-M4) of the butanolic layer of T. ornata extract separated by the Sephadex LH20 were applied to NO assay. Fraction M2 showed the most potent inhibitory activity on NO production induced by LPS. Hence, fraction M2 was further separated and purified using HPLC to yield several compounds including three sulfoquinovosylmonoacylglycerols (SQMGs). Compound 1 was obtained as a colorless oil and its molecular formula was determined as $\mathrm{C}_{27} \mathrm{H}_{50} \mathrm{O}_{12} \mathrm{~S}$ by the combination of negative HRESIMS and the ${ }^{13} \mathrm{C}$ NMR spectrum. The ${ }^{1} \mathrm{H}$ NMR spectrum of 1 showed signals distributed in the range of 3.1-4.3 ppm, and a triplet at $\delta_{\mathrm{H}} 2.36$, a multiplet at $\delta_{\mathrm{H}} 1.61$, a broad singlet at $\delta_{\mathrm{H}} 1.31$ and a triplet peak at $\delta_{\mathrm{H}}$ 0.89 , indicating characteristic signals for a class of glycerolipids. An $\alpha$-form glycopyranose was assigned by the
COSY correlations from the anomeric proton at $\delta_{\mathrm{H}} 4.77 \mathrm{U}$ $=3.7 \mathrm{~Hz}$ ). The coupling constant of each proton and the carbon chemical shifts at C-6", along with the molecular formula, suggested a 6-deoxy-6-sulfo- $\alpha$ - $D$-glucopyrose moiety. The chemical shifts of the protons and carbons of the unit were consistent with the those of the known ones (Hirao et al. 2012). Further analysis of the COSY and TOCSY spectra led to assign the position of one olefinic group within the long carbon chain to be $\Delta 7^{\prime}$. This was also corroborated by the heteronuclear multiple bond correlation (HMBC) correlations from $\mathrm{H}-2^{\prime}, \mathrm{H}-3^{\prime}, \mathrm{H}-5^{\prime}$ to C-4' and from H-4', H-6', H-7' to C-5'. The COSY correlation from the olefinic protons $\left(\mathrm{H}-\mathrm{8}^{\prime}\right)$ to the remaining oxymethine proton allowed the hydroxy group to be attached at C-9'. In addition, the position of the functional groups in the carbon chain was determined by MS/MS analysis of the carbon chain cleaved by hydrolysis of 1 with $0.1 \mathrm{~N} \mathrm{HCl}$ (Supplementary Figs S1-S16). The geometry of the olefinic group was established as $E$ by the large proton coupling constant $U=15.4 \mathrm{~Hz}$ ). The observation of carbons paired from C-3' to C-11' revealed 

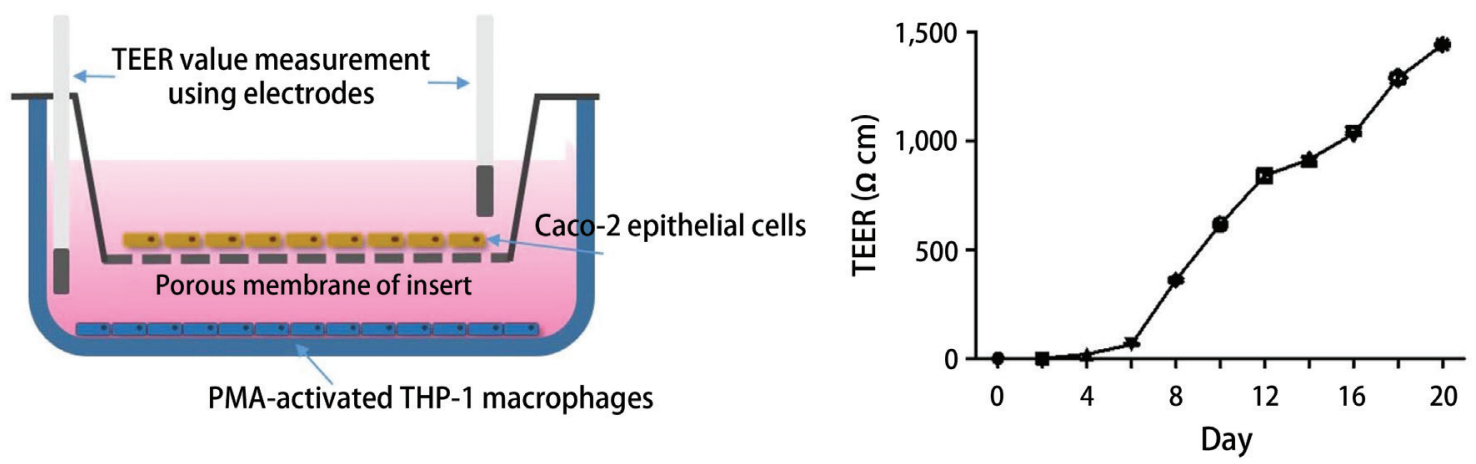

Fig. 3. Co-culture system consists of Caco-2 epithelial cells and PMA (phorbol-12-myristate-13-acetate)-differentiated THP-1 macrophage cells (left), and TEER values for 21 days (right).

that compound 1 is a mixture of two epimers consisting of $9(R)$ and $9(S)$. Finally, HMBC correlations from H-3 to $\mathrm{C}-1$ " and from $\mathrm{H}-1$ to the carbonyl carbon at C-1' established the planar structure of 1 . Thus, compound 1 was determined as 1-O-[(7E)-9-hydroxyoctadec-7enoyl]-3-O-(6-sulfo- $\alpha$-D-quinovopyranosyl)-sn-glycerol. Compared with 1, compounds 2 and 3 did not display the downfield shifted proton signals corresponding to olefinic groups, but consisted of saturated acyl groups. From the analysis of NMR and HRESIMS, compounds 2 and 3 were identified as 1-stearoyl-3-O-(6-sulfo- $\alpha-D$ quinovopyranosyl)-sn-glycerol and 1-palmitoyl-3-O-(6sulfo- $\alpha$ - $D$-quinovopyranosyl)-sn-glycerol, respectively (Sakamoto et al. 2000, Hanashima et al. 2001).

Anti-inflammatory activities of the isolated compounds 1-3 were screened using THP-1 macrophage cells activated by LPS and IFN $\gamma$ treatment. Prior to evaluating anti-inflammatory activities of 1-3, the cytotoxicities of the compounds were measured using CCK- 8 assay. All compounds showed no cytotoxicity at the concentration range up to $10 \mu \mathrm{M}$ (cell viability $>98 \%$ of control). To evaluate the inhibitory activity of 1-3 on NO production, THP-1 cells were treated with each compound (1, 5, and $10 \mu \mathrm{M})$ for $1 \mathrm{~h}$ and then challenged with LPS $(1 \mu \mathrm{g}$ $\left.\mathrm{mL}^{-1}\right)$ and IFN $\gamma\left(10 \mathrm{ng} \mathrm{mL}^{-1}\right)$. After $24 \mathrm{~h}$ of incubation, the content of NO that is released into culture medium was detected using DAF-DA. Among the compounds tested, 1 and 2 showed the significant inhibition on NO production induced by LPS and IFN $\gamma$, while 3 was inactive. Inhibitory activities of 1-3 on $\mathrm{PGE}_{2}$ production were further investigated (Fig. 2). As a result, the pretreatment of cells with $\mathbf{1}$ or 2 for $24 \mathrm{~h}$ led to a significant decrease of LPS and IFN $\gamma$-induced $\mathrm{PGE}_{2}$ production in a concentrationdependent manner, whereas a mild decrease by 3 was observed at the concentration of $10 \mu \mathrm{M}$.

\section{The effects of 1 and 2 on the expression of pro- inflammatory proteins and the phosphorylation of mitogen-activated protein kinase family in intestinal co-culture system}

Recently, the advanced and novel co-culture model of Caco-2 and PMA-differentiated THP-1 cells that resembles human intestine has been established (Kämpfer et al. 2017). This in vitro model is featured by representing numerous hallmarks of intestinal inflammation. During developing co-culture model, TEER value is extensively used to measure the resistance of tight junctions of cell monolayer. The TEER was measured using an Ohmmeter to assess the tightness of the Caco-2 cell layer on the apical side of the insert as well as the barrier integrity throughout co-culture with THP-1 cells. In our co-culture system, TEER of Caco-2 layer subsequently increased at 4 days after plating and reached the maximum value at day 21 (Fig. 3). In this co-culture system, the effects of 1 and 2 on the expression of iNOS and COX-2 as well as the phosphorylation of mitogen-activated protein kinase (MAPK) family was measured to evaluate the action mechanism of the compounds regulating intestinal inflammation. As shown in Fig. 4, western blot analysis showed that the expression levels of iNOS and COX-2 were upregulated by co-treatment of LPS and IFN $\gamma$, whereas the pretreatment of cells with 1 or $2(1,5$, and $10 \mu \mathrm{M})$ significantly attenuated this upregulation. In addition, the induced phosphorylation of p38, ERK1/2, and JNK induced by LPS and IFN $\gamma$ was attenuated by pretreatment of 1 or 2 . At the concentration of $1 \mu \mathrm{M}$, the significant decrease on phospho-ERK1/2 and phospho-JNK by 1 and 2, respectively, were observed (Fig. 5). 


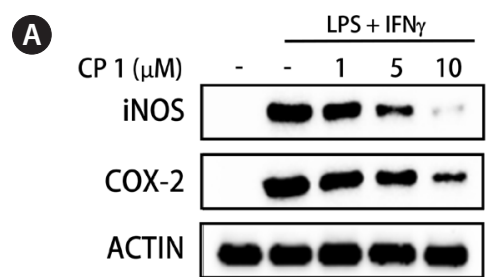

B

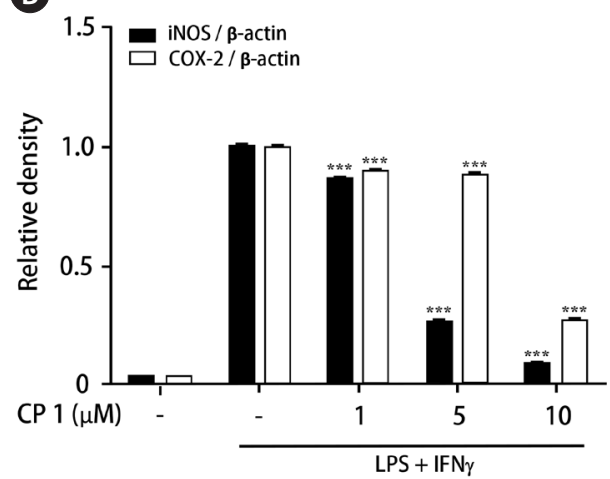

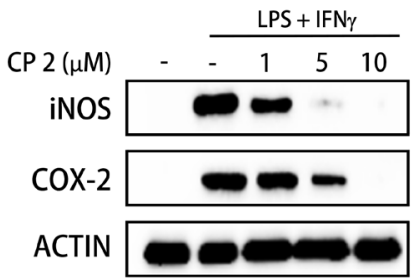

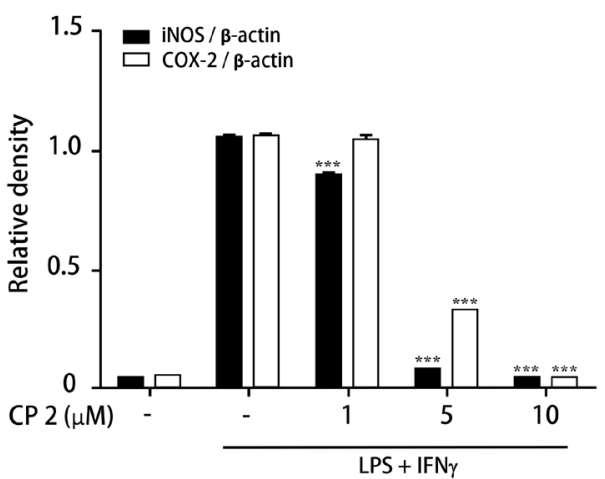

Fig. 4. Compounds 1 and 2 down-regulated the expression of inducible nitric oxide synthase (iNOS) and cyclooxygenase 2 (COX-2) in intestinal co-culture system. Compounds 1 or $\mathbf{2}(1,5$, and $10 \mu \mathrm{M})$ were individually treated into the apical compartment of the Caco-2/THP-1 co-culture system. After $1 \mathrm{~h}$, lipopolysaccharide (LPS; $1 \mathrm{\mu g} \mathrm{mL}^{-1}$ ) and interferon $\gamma$ (IFNY; $10 \mathrm{ng} \mathrm{mL}^{-1}$ ) were co-treated to the basolateral compartment. The expression levels of iNOS and COX-2 in cells were analyzed by western blot after $24 \mathrm{~h}$ of LPS + IFN $y$ challenge. (A) The representative blots. (B) The calculated intensities after normalization to $\beta$-actin. $C P$, compound. Results are presented as the mean \pm standard deviation of triplicate experiments. ${ }^{* * *} \mathrm{p}<0.001$ compared to LPS-treated cells.
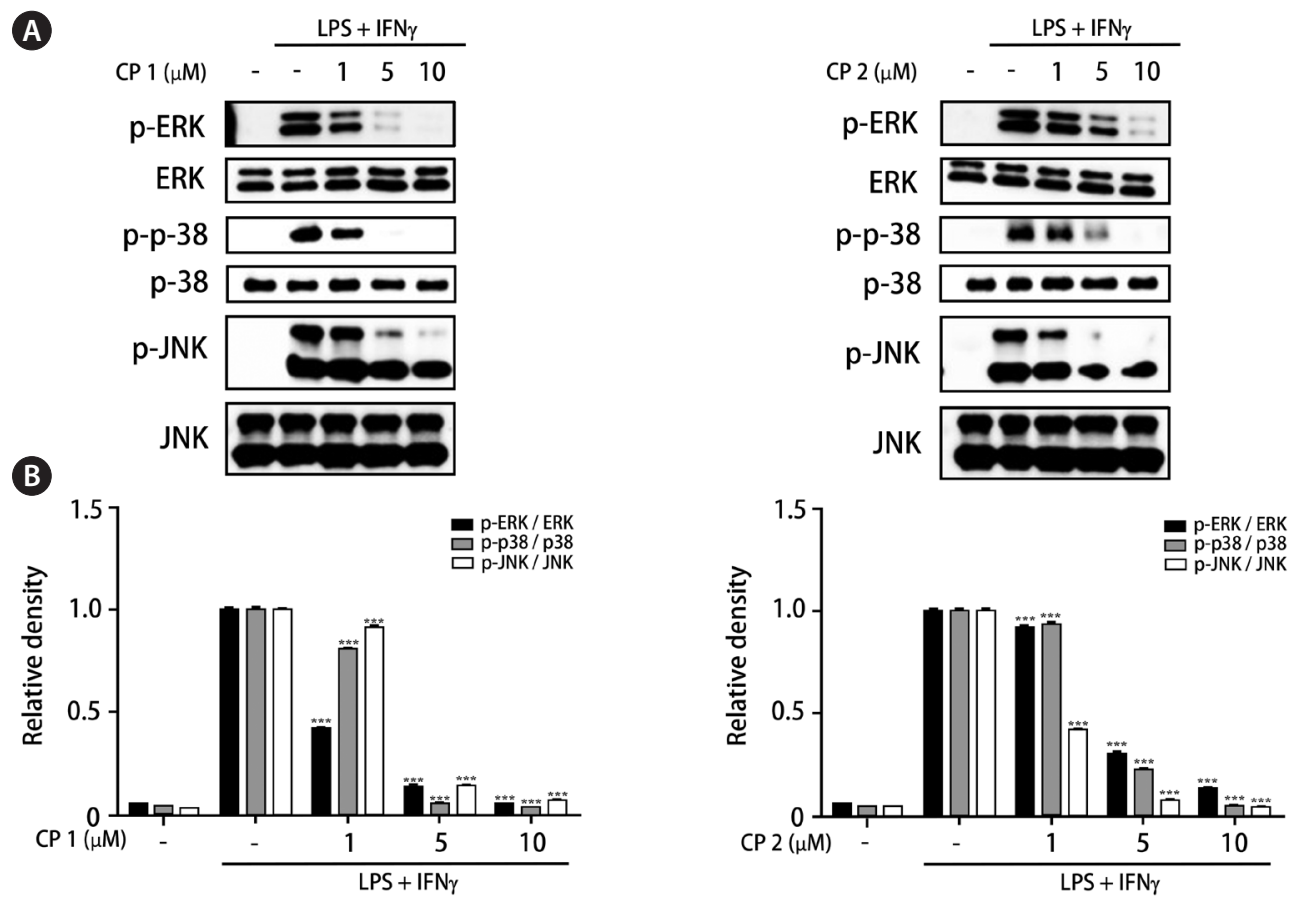

Fig. 5. Compounds 1 and 2 attenuated the phosphorylation of mitogen-activated protein kinase (MAPK) family in intestinal co-culture system. Compounds 1 or $2(1,5$, and $10 \mu \mathrm{M})$ were individually treated into the apical compartment of the Caco-2/THP-1 co-culture system. After $1 \mathrm{~h}$, lipopolysaccharide (LPS; $1 \mu \mathrm{g} \mathrm{mL}^{-1}$ ) and interferon $\gamma$ (IFNү; $10 \mathrm{ng} \mathrm{mL}^{-1}$ ) were co-treated to the basolateral compartment. The phosphorylation levels of MAPKs (ERK, p38, and JNK) were analyzed by western blot after 15-30 min of LPS + IFNy challenge. (A) The representative blots. (B) The calculated intensities after normalization to $\beta$-actin. $C P$, compound. Results are presented as the mean \pm standard deviation of triplicate experiments. ${ }^{* * *} p<$ 0.001 compared to LPS-treated cells. 


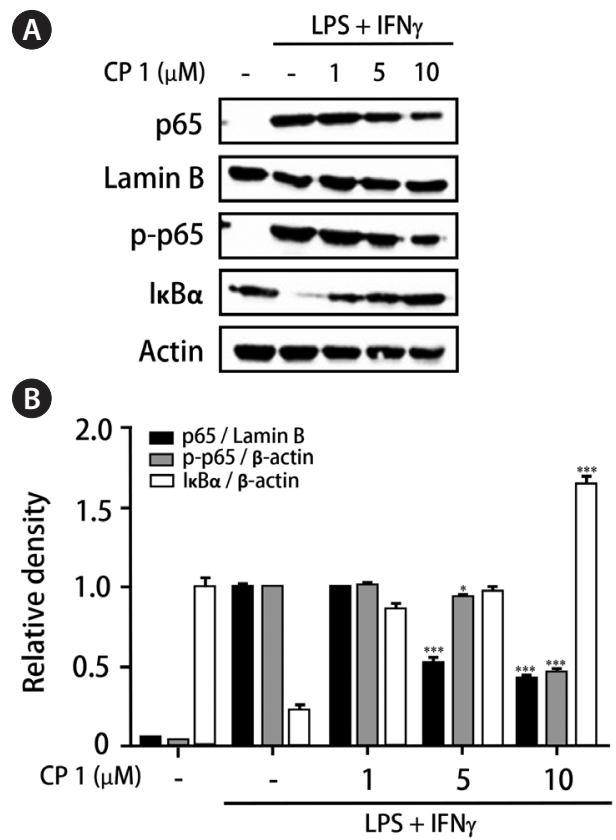

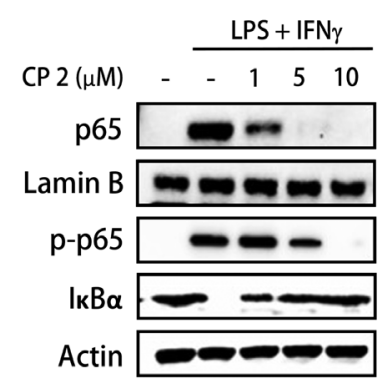

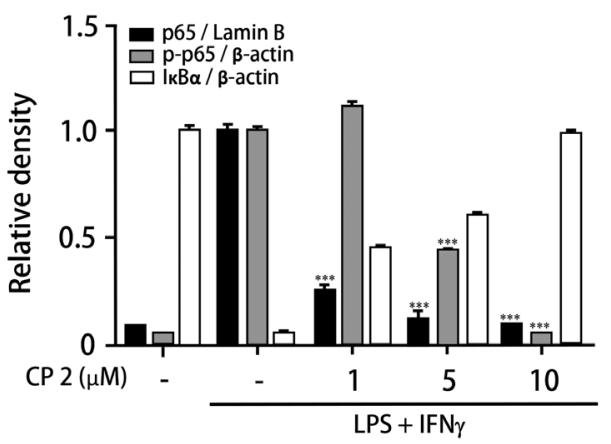

Fig. 6. Compounds 1 and 2 inhibited NF-KB translocation into the nucleus in intestinal co-culture system. Compounds 1 or $2(1,5$, and $10 \mu \mathrm{M})$ were individually added into the apical compartment of the Caco-2/THP-1 co-culture system. After $1 \mathrm{~h}$, lipopolysaccharide (LPS; $\left.1 \mu \mathrm{g} \mathrm{mL} \mathrm{L}^{-1}\right)$ and interferon $\gamma$ (IFNץ; $10 \mathrm{ng} \mathrm{mL}^{-1}$ ) were co-treated to the basolateral compartment and the cells were incubated overnight. Cell extracts were biochemically separated into nuclear and cytoplasmic fractions, and the expression of p65, phosphorylated-p65, Lamin B, and IkBa in cells was analyzed by western blot. (A) The representative blots. (B) The calculated intensities after normalization to Lamin B (nucleus) or $\beta$-actin (cytosol and whole cell). CP, compound. Results are presented as the mean \pm standard deviation of triplicate experiments. ${ }^{*} p<0.05$ and ${ }^{* * *} p<0.001$ compared to LPS-treated cells.

\section{The effects of 1 and 2 on the nucleus transloca- tion of nuclear factor-kB and its inhibitor, IKB-a in intestinal co-culture system}

It has been known that interaction of p65 unit of nuclear factor- $\mathrm{\kappa B}(\mathrm{NF}-\kappa \mathrm{K})$ with specific gene sets promotes subsequent transcription and expression of inflammatory mediators in macrophages (Aggarwal et al. 2004, Sanjeewa et al. 2019). Based on the inhibitory activities of $\mathbf{1}$ and $\mathbf{2}$ on the expressions of pro-inflammatory proteins and MAPK family, the effects of these compounds regulating p65 localization in nucleus and cytoplasm have been observed. After treatment of cells with compounds followed by LPS and IFN $\gamma$ challenge, whole cell lysates were biochemically fractionated into nuclear and cytoplasmic extracts to measure localization of p65 and phosphorylated p65. As shown in Fig. 6, the treatment of cells with 1 or $2(1,5$, and $10 \mu \mathrm{M})$ markedly inhibited the phosphorylation of p65 in cytoplasm and weakened the translocation of p65 into nucleus. Significantly upregulated total levels of IкB- $\alpha$ protein by $\mathbf{1}$ and $\mathbf{2}$ in the cytoplasm may explain the enhanced binding of IкB- $\alpha$ to $p 65$, which indicates that NF- $\mathrm{kB}$ access to the nucleus binds to the promoter can be prevented. The increase of IкB- $\alpha$ level in cytoplasm was more significant by 1 at the concentration of $10 \mu \mathrm{M}$. These results suggest that interfering with the p65 subunit of NF- $\mathrm{kB}$ and a specific set of target genes by 1 or 2 results in subsequent down-regulation of transcription and expression of inflammatory mediators (Oeckinghaus and Ghosh 2009, Saegusa et al. 2010).

\section{DISCUSSION}

T. ornata is a brown alga common in the world. This seaweed is widely consumed as a functional food by Asians due to its antioxidant properties and is also used as a folk medicine for various diseases. T. ornata has been reported to exhibit a broad range of biological activities, including antibacterial, anticoagulant, antiviral, antitumor, hepatoprotective activity, and treatment for parasitic infections (Vijayabaskar and Shiyamala 2011, Chia et al. 2015, Abdella et al. 2016, Canoy and Bitacura 2018). Regarding anti-inflammatory properties of T. ornata, Subash et al. (2016) reported an anti-inflammatory effect with the bioactive components of T. ornata. The granu- 
loma weight was reduced and biochemical and inflammatory markers were improved by aqueous extract of $T$. ornata in cotton pellet induced granuloma model in rats. Using gas chromatography-mass spectrometry (GCMS), fucoidan was characterized as an active constituent in T. ornata. Fucoidan referred to the sulfated polysaccharides containing fucose that is contained in cell wall of brown algae. Numerous literatures demonstrated that fucoidan exhibits potential anti-inflammatory activity in vitro and in vivo. Fucoidan extracted from T. ornata from the Maldives inhibited expressions of inflammatory cytokines and protein in RAW264.7 macrophages. Also, the level of reactive oxygen species and NO was reduced by fucoidan treatment in zebrafish embryo model (Jayawardena et al. 2019). Anti-inflammatory action of the sulfated polysaccharide of $T$. ornata was further investigated in Complete Freund's Adjuvant induced arthritis in rats. Ananthi et al. (2017) revealed that the sulfated polysaccharide purified from T. ornata inhibited inflammation and bone damage at very low dose itself that was evidenced by the significant reduction in paw volume and arthritic score. Besides the sulfated polysaccharides, a phytochemical analysis to identify the biologically active constituents in T. ornata deduced the presence of saponin, alkaloids, amino acids, fixed oil, fat and phenolic compounds by GC-MS and Fourier transform infrared spectroscopy experiments (Deepak et al. 2017). However, characterization of the metabolites in T. ornata based on the full assignment by NMR experiments are limited. The aim of this study was to identify anti-inflammatory metabolites of T. ornata through isolation and structure elucidation using 1D, 2D-NMR, and MS analysis. Also, we attempted to reveal anti-inflammatory potential for the isolated compounds regulating intestinal inflammation using in vitro co-culture system.

Through activity-guided fractionation and isolation, three SQMGs including one new compound were successfully isolated and identified. A new compound 1, which possesses one hydroxy group and one double bond on the carbon chain, was obtained as a mixture of the two epimers. Compound 3 was isolated in large quantities compared to $\mathbf{1}$ and $\mathbf{2}$, but compounds $\mathbf{1}$ and $\mathbf{2}$ showed the significant inhibition against inflammatory mediators in THP-1 macrophage cells. Interestingly, it was found that 1 and 2 with carbon chains of equal length (C18) are active while 3 with $\mathrm{C} 16$ chain are inactive. For evaluation of anti-inflammatory property of bioactive compounds, 1 and 2 were further investigated in co-culture system established using human-originated epithelial-like Caco-2 and THP-1 macrophage cells.
Abnormal and persistent inflammatory responses to commensal microbes in genetically sensitive hosts are thought to be the main cause of IBD. In IBD patients, immune cells have been found to release abnormally high levels of pro-inflammatory cytokines compared to normal tissues (MacDermott 1999). In addition, markedly enhanced secretion of these downstream pre-inflammatory cytokines such as tumor necrosis factor $\alpha$ (TNF- $\alpha$ ), interleukin (IL)- $1 \beta$, and IL- 6 is observed in patients with UC and CD. Overexpressed TNF- $\alpha$, IL- $1 \beta$, iNOS, and COX2 are involved in the development of colitis (Ogata and Hibi 2003, Pettus et al. 2003, Pan et al. 2008). Correspondingly, agents that block the overproduction of these cytokines are proposed to be effective in treating IBD. The first choice of drugs for patients with mild to moderate IBD is anti-inflammatory drugs such as amino salicylate and corticosteroids. Amino salicylates are known to be effective in calming inflammation in the digestive track. However, the side effects including headache, nausea, and diarrhea in high dose limit the use of this medication. In THP-1 macrophage cells, treatment of cells with 1 or 2 inhibited the production of $\mathrm{NO}$ and $\mathrm{PGE}_{2}$ stimulated by LPS and IFN $\gamma$. Also, in co-culture system established herein, the expressions of pro-inflammatory proteins, iNOS and COX-2 were markedly attenuated by 1 or 2 in response to inhibition on MAPKs (p38, ERK1/2, and JNK) phosphorylation.

$\mathrm{NF}-\mathrm{kB}$ is an essential and ubiquitous transcription factor that controls immune and inflammatory signal transduction by regulating the expression of related genes (Lappas et al. 2002, Aggarwal et al. 2004). Since $\mathrm{NF}-\kappa \mathrm{B}$ binds to the proximal promoters of the COX-2 and TNF- $\alpha$ genes, the inhibition of DNA-binding activity of $N F-\kappa B$ corresponds to the inhibition of the expression of inflammatory mediators, iNOS, COX-2, and TNF- $\alpha$ (Economou et al. 1989). In inactivated cells, NF-кB complexes containing subunits p50 and p65 are located in the cytoplasm combined with IкB- $\alpha$. When cells are activated, IкB- $\alpha$ is phosphorylated by the IкB kinase complex and dissociates from NF- $\mathrm{kB}$ to allow translocation of NF- $\mathrm{kB}$ to the nucleus. Translocated NF- $\mathrm{kB}$ promotes subsequent transcription and expression of inflammatory mediators (Oeckinghaus and Ghosh 2009, Saegusa et al. 2010). Based on the inhibitory effects of 1 and 2 on the expression of inflammatory cytokines and proteins, the action mechanisms of these compounds involved in NF- $\kappa \mathrm{B}$ localization in nucleus and cytoplasm of THP- 1 macrophges were observed. In THP-1 macrophages cocultured with Caco-2 cells, the treatment of 1 and 2 attenuated the phosphorylation of p65 and upregulated 
the expression level of IкB- $\alpha$ in cytoplasm, leading to the enhanced interactions of $\mathrm{p} 65$ subunit of NF- $\mathrm{kB}$ with IкB- $\alpha$. The enhanced binding of IкB- $\alpha$ with p65 results in cytoplasmic retention of NF- $\mathrm{kB}$ complex, thereby preventing the access of NF- $\mathrm{kB}$ to the nucleus for binding the target gene promoter. Above results suggest that the two SQMGs isolated from T. ornata inhibits the expression of pro-inflammatory mediators via regulation of NF$\kappa B$ pathway.

A new SQMG together with two known SQMGs were isolated from the brown alga T. ornata. The anti-inflammatory potential of the isolated compounds was evaluated in an in vitro co-culture system combining epithelial Caco-2 cells and THP-1 macrophages similar to the intestinal environment. The two SQMGs isolated from T. ornata showed potent anti-inflammatory activity by down-regulating the expression of iNOS and COX-2 and attenuating nuclear translocation of NF- $\mathrm{kB}$. Given that NF- $\kappa B$ is considered a master switch that regulates inflammation in macrophages, the present study supports the potential use of $T$. ornata and its bioactive metabolites as therapeutics for IBD.

\section{ACKNOWLEDGEMENTS}

This work was supported by a grant from the Marine Biotechnology Program (20170488) funded by the Ministry of Oceans and Fisheries, Korea.

\section{SUPPLEMENTARY MATERIALS}

Supplementary Fig. S1. High-performance liquid chromatography (HPLC) chromatogram for the separation of M2 fraction (https://e-algae.org).

Supplementary Fig. S2. (A) High resolution negative mass spectrometry (MS) and tandem mass spectrometry (MS/MS) spectra. (B) Optical rotation value for 1 (https://e-algae.org).

Supplementary Fig. S3. Infrared spectrum of 1 (https://e-algae.org).

Supplementary Fig. S4. ${ }^{1} \mathrm{H}$ NMR spectrum of 1 (https://e-algae.org).

Supplementary Fig. S5. ${ }^{13} \mathrm{C}$ NMR spectrum of 1 (https://e-algae.org).

Supplementary Fig. S6. COSY NMR spectrum of 1 (https://e-algae.org).

Supplementary Fig. S7. TOCSY NMR spectrum of 1 (https://e-algae.org).
Supplementary Fig. S8. HSQC NMR spectrum of 1 (blue cross peaks, $\mathrm{CH}$ or $\mathrm{CH}_{3}$; black cross peaks, $\mathrm{CH}_{2}$ ) (https://e-algae.org).

Supplementary Fig. S9. HMBC NMR spectrum of 1 (https://e-algae.org).

Supplementary Fig. S10. ROESY NMR spectrum of 1 (https://e-algae.org).

Supplementary Fig. S11. Tandem mass spectrometry (MS/MS) analysis for the cleaved linear carbon chain of $\mathbf{1}$ (https://e-algae.org).

Supplementary Fig. S12. (A) High resolution negative mass spectrometry (MS) and tandem mass spectrometry (MS/MS) spectra. (B) Optical rotation value for 2 (https://e-algae.org).

Supplementary Fig. S13. ${ }^{1} \mathrm{H}$ NMR spectrum of 2 (https://e-algae.org).

Supplementary Fig. S14. ${ }^{13} \mathrm{C}$ NMR spectrum of 2 (https://e-algae.org).

Supplementary Fig. S15. (A) High resolution negative mass spectrometry (MS) and tandem mass spectrometry (MS/MS) spectra. (B) Optical rotation value for $\mathbf{3}$ (https://e-algae.org).

Supplementary Fig. S16. ${ }^{1} \mathrm{H}$ NMR spectrum of 3 (https://e-algae.org).

\section{REFERENCES}

Abdella, E. M., Mahmoud, A. M. \& El-Derby, A. M. 2016. Brown seaweeds protect against azoxymethane-induced hepatic repercussions through up-regulation of peroxisome proliferator-activated receptor gamma and attenuation of oxidative stress. Pharm. Biol. 54:24962504.

Abraham, C. \& Cho, J. H. 2009. Inflammatory bowel disease. N. Engl. J. Med. 361:2066-2078.

Aggarwal, B. B., Takada, Y., Shishodia, S., Gutierrez, A. M., Oommen, O. V., Ichikawa, H., Baba, Y. \& Kuman, A. 2004. Nuclear transcription factor NF-kappa B: role in biology and medicine. Indian J. Exp. Biol. 42:341-353.

Alves, C., Silva, J., Pinteus, S., Gaspar, H., Alpoim, M. C., Botana, L. M. \& Pedrosa, R. 2018. From marine origin to therapeutics: the antitumor potential of marine algaederived compounds. Front. Pharmacol. 9:777.

Ananthi, S., Gayathri, V., Malarvizhi, R., Bhardwaj, M. \& Vasanthi, H. R. 2017. Anti-arthritic potential of marine macroalga Turbinaria ornata in Complete Freund's Adjuvant induced rats. Exp. Toxicol. Pathol. 69:672-680.

Asari, F., Kusumi, T. \& Kakisawa, H. 1989. Turbinaric acid, a cytotoxic secosqualene carboxylic acid from the brown 
alga Turbinaria ornata. J. Nat. Prod. 52:1167-1169.

Blunt, J. W., Copp, B. R., Keyzers, R. A., Munro, M. H. G. \& Prinsep, M. R. 2013. Marine natural products. Nat. Prod. Rep. 30:237-323.

Bouma, G. \& Strober, W. 2003. The immunological and genetic basis of inflammatory bowel disease. Nat. Rev. Immunol. 3:521-533.

Canoy, J. L. \& Bitacura, J. G. 2018. Cytotoxicity and antiangiogenic activity of Turbinaria ornata Agardh and Padina australis Hauck ethanolic extracts. Anal. Cell Pathol. (Amst.) 2018:3709491.

Cardozo, K. H. M., Guaratini, T., Barros, M. P., Falcão, V. R., Tonon, A. P., Lopes, N. P., Campos, S., Torres, M. A., Souza, A. O., Colepicolo, P. \& Pinto, E. 2007. Metabolites from algae with economical impact. Comp. Biochem. Physiol. Part C Toxicol. Pharmacol. 146:60-78.

Chia, Y. Y., Kanthimathi, M. S., Khoo, K. S., Rajarajeswaran, J., Cheng, H. M. \& Yap, W. S. 2015. Antioxidant and cytotoxic activities of three species of tropical seaweeds. BMC Complement. Altern. Med. 15:339.

Daigneault, M., Preston, J. A., Marriott, H. M., Whyte, M. K. B. \& Dockrell, D. H. 2010. The identification of markers of macrophage differentiation in PMA-stimulated THP1 cells and monocyte-derived macrophages. PLoS ONE 5:e8668.

Deepak, P., Sowmiya, R., Balasubramani, G. \& Perumal, P. 2017. Phytochemical profiling of Turbinaria ornata and its antioxidant and anti-proliferative effects. J. Taibah Univ. Med. Sci. 12:329-337.

Economou, J. S., Rhoades, K., Essner, R., McBride, W. H., Gasson, J. C. \& Morton, D. L. 1989. Genetic analysis of the human tumor necrosis factor $\alpha /$ cachectin promoter region in a macrophage cell line. J. Exp. Med. 170:321-326.

Faulkner, D. J. 2001. Marine natural products. Nat. Prod. Rep. 18:1-49.

Fernando, I. P. S., Kim, K. -N., Kim, D. \& Jeon, Y. -J. 2019. Algal polysaccharides: potential bioactive substances for cosmeceutical applications. Crit. Rev. Biotechnol. 39:99113.

Hanashima, S., Mizushina, Y., Yamazaki, T., Ohta, K., Takahashi, S., Sahara, H., Sakaguchi, K. \& Sugawar, F. 2001. Synthesis of sulfoquinovosylacylglycerols, inhibitors of eukaryotic DNA polymerase $\alpha$ and $\beta$. Bioorg. Med. Chem. 9:367-376.

Hirao, S., Tara, K., Kuwano, K., Tanaka, J. \& Ishibashi, F. 2012. Algicidal activity of glycerolipids from brown alga Ishiga sinicola toward red tide microalgae. Biosci. Biotechnol. Biochem. 76:372-374.

Jayawardena, T. U., Fernando, I. P. S., Lee, W. W., Sanjeewa, K. K. A., Kim, H. -S., Lee, D. -S. \& Jeon, Y. -J. 2019. Isola- tion and purification of fucoidan fraction in Turbinaria ornata from the Maldives: inflammation inhibitory potential under LPS stimulated conditions in in-vitro and in-vivo models. Int. J. Biol. Macromol. 131:614-623.

Kämpfer, A. A. M., Urbán, P., Gioria, S., Kanase, N., Stone, V. \& Kinsner-Ovaskainen, A. 2017. Development of an in vitro co-culture model to mimic the human intestine in healthy and diseased state. Toxicol. In Vitro 45:31-43.

Kleiveland, C. R. 2015. Chapter 18: Co-culture Caco-2/immune cells. In Verhoeckx, K., Cotter, P., López-Expósito, I., Kleiveland, C., Lea, T., Mackie, A., Requena, T., Swiatecka, D. \& Wichers, H. (Eds.) The Impact of Food Bioactives on Health: In Vitro and Ex Vivo Models. Springer, Cham, pp. 135-140.

Lappas, M., Permezel, M., Georgiou, H. M. \& Rice, G. E. 2002. Nuclear factor kappa B regulation of proinflammatory cytokines in human gestational tissues in vitro. Biol. Reprod. 67:668-673.

Lennernäs, H., Palm, K., Fagerholm, U. \& Artursson, P. 1996. Comparison between active and passive drug transport in human intestinal epithelial (caco-2) cells in vitro and human jejunum in vivo. Int. J. Pharm. 127:103-107.

Loftus, E. V. Jr. \& Sandborn, W. J. 2002. Epidemiology of inflammatory bowel disease. Gastroenterol. Clin. North Am. 312:1-20.

MacDermott, R. P. 1999. Chemokines in the inflammatory bowel diseases. J. Clin. Immunol. 19:266-272.

Oeckinghaus, A. \& Ghosh, S. 2009. The NF- $\kappa$ B family of transcription factors and its regulation. Cold Spring Harb. Perspect. Biol. 1:a000034.

Ogata, H. \& Hibi, T. 2003. Cytokine and anti-cytokine therapies for inflammatory bowel disease. Curr. Pharm. Des. 9:1107-1113.

Pan, M. -H., Hsieh, M. -C., Hsu, P. -C., Ho, S. -Y., Lai, C. -S., Wu, H., Sang, S. \& Ho, C. -T. 2008. 6-Shogaol suppressed lipopolysaccharide-induced up-expression of iNOS and COX-2 in murine macrophages. Mol. Nutr. Food Res. 52:1467-1477.

Pettus, B., Bielawski, J., Porcelli, A. M., Reames, D. L., Johnson, K. R., Morrow, J., Chalfant, C. E., Obeid, L. M. \& Hannun, Y. A. 2003. The sphingosine kinase 1/sphingosine-1-phosphate pathway mediates COX-2 induction and $\mathrm{PGE}_{2}$ production in response to TNF-alpha. FASEB J. 17:1411-1421.

Rubas, W., Jezyk, N. \& Grass, G. M. 1993. Comparison of the permeability characteristics of a human colonic epithelial (Caco-2) cell line to colon of rabbit, monkey, and dog intestine and human drug absorption. Pharm. Res. 10:113-118.

Saegusa, M., Hashimura, M. \& Kuwata, T. 2010. Pin1 acts as 
a modulator of cell proliferation through alteration in NF- $\kappa$ B but not $\beta$-catenin/TCF4 signalling in a subset of endometrial carcinoma cells. J. Pathol. 222:410-420.

Sakamoto, B., Hokama, Y., Horgen, F. D., Scheuer, P. J., Kan, Y. \& Nagai, H. 2000. Isolation of a sulfoquinovosyl monoacylglycerol from Bryopsis sp. (Chlorophyta): identification of a factor causing a possible species-specific ecdysis response in Gambierdiscus toxicus (Dinophyceae). J. Phycol. 36:924-931.

Sanjeewa, K. K. A., Fernando, I. P. S., Kim, S. -Y., Kim, W. -S., Ahn, G., Jee, Y. \& Jeon, Y. -J. 2019. Ecklonia cava (Laminariales) and Sargassum horneri (Fucales) synergistically inhibit the lipopolysaccharide-induced inflammation via blocking NF- $\kappa \mathrm{B}$ and MAPK pathways. Algae 34:45-56.

Sheu, J. H., Wang, G. H., Sung, P. J., Chiu, Y. H. \& Duh, C. Y. 1997. Cytotoxic sterols from the formosan brown alga Turbinaria ornata. Planta Med. 63:571-572.

Subash, A., Veeraraghavan, G., Sali, V. K., Bhardwaj, M. \&
Vasanthi, H. R. 2016. Attenuation of inflammation by marine alga Turbinaria ornata in cotton pellet induced granuloma mediated by fucoidan like sulphated polysaccharide. Carbohydr. Polym. 151:1261-1268.

Vijayabaskar, P. \& Shiyamala, V. 2011. Antibacterial activities of brown marine algae (Sargassum wightii and Turbinaria ornata) from the Gulf of Mannar Biosphere Reserve. Adv. Biol. Res. 5:99-102.

Vijayabaskar, P. \& Shiyamala, V. 2012. Antioxidant properties of seaweed polyphenol from Turbinaria ornata (Turner) J. Agardh, 1848. Asian Pac. J. Trop. Biomed. 2:S90-S98.

Wang, H. -M. D., Li, X. -C., Lee, D. -J. \& Chang, J. -S. 2017. Potential biomedical applications of marine algae. Bioresour. Technol. 244:1407-1415.

Zubia, M., Payri, C. \& Deslandes, E. 2008. Alginate, mannitol, phenolic compounds and biological activities of two range-extending brown algae, Sargassum mangarevense and Turbinaria ornata (Phaeophyta: Fucales), from Tahiti (French Polynesia). J. Appl. Phycol. 20:1033-1043. 